\title{
Dry needling for spine related disorders: a scoping review
}

\author{
Matthew F. Funk ${ }^{*}$ and Aric J. Frisina-Deyo
}

\begin{abstract}
Introduction/Background: The depth and breadth of research on dry needling (DN) has not been evaluated specifically for symptomatic spine related disorders (SRD) from myofascial trigger points (TrP), disc, nerve and articular structures not due to serious pathologies. Current literature appears to support DN for treatment of TrP. Goals of this review include identifying research published on DN treatment for SRD, sites of treatment and outcomes studied.
\end{abstract}

Methods: A scoping review was conducted following Levac et al.'s five part methodological framework to determine the current state of the literature regarding DN for patients with SRD.

Results: Initial and secondary search strategies yielded 55 studies in the cervical (C) region (71.43\%) and 22 in the thoracolumbar-pelvic (TLP) region (28.57\%). Most were randomized controlled trials (60\% in C, 45.45\% in TLP) and clinical trials (18.18\% in C, 22.78\% in TLP). The most commonly treated condition was TrP for both the C and TLP regions. In the $\mathrm{C}$ region, DN was provided to 23 different muscles, with the trapezius as treatment site in $41.88 \%$ of studies. DN was applied to 31 different structures in the TLP region. In the $\mathrm{C}$ region, there was one treatment session in 23 studies (41.82\%) and 2-6 treatments in 25 (45.45\%\%). For the TLP region, one DN treatment was provided in 8 of the 22 total studies (36.36\%) and 2-6 in 9 (40.9\%). The majority of experimental designs had DN as the sole intervention. For both $C$ and TLP regions, visual analogue scale, pressure pain threshold and range of motion were the most common outcomes.

Conclusion: For SRD, DN was primarily applied to myofascial structures for pain or TrP diagnoses. Many outcomes were improved regardless of diagnosis or treatment parameters. Most studies applied just one treatment which may not reflect common clinical practice. Further research is warranted to determine optimal treatment duration and frequency. Most studies looked at DN as the sole intervention. It is unclear whether DN alone or in addition to other treatment procedures would provide superior outcomes. Functional outcome tools best suited to tracking the outcomes of DN for SRD should be explored.

Keywords: Spine, Neck pain, Back pain, Myofascial pain syndrome, Trigger point, Pain, Outcome assessment

* Correspondence: mfunk@bridgeport.edu

University of Bridgeport College of Health Sciences, School of Chiropractic,

126 Park Avenue, Bridgeport, CT 06604, USA

(c) The Author(s). 2020 Open Access This article is licensed under a Creative Commons Attribution 4.0 International License, which permits use, sharing, adaptation, distribution and reproduction in any medium or format, as long as you give appropriate credit to the original author(s) and the source, provide a link to the Creative Commons licence, and indicate if changes were made. The images or other third party material in this article are included in the article's Creative Commons licence, unless indicated otherwise in a credit line to the material. If material is not included in the article's Creative Commons licence and your intended use is not permitted by statutory regulation or exceeds the permitted use, you will need to obtain permission directly from the copyright holder. To view a copy of this licence, visit http://creativecommons.org/licenses/by/4.0/ The Creative Commons Public Domain Dedication waiver (http://creativecommons.org/publicdomain/zero/1.0/) applies to the data made available in this article, unless otherwise stated in a credit line to the data. 


\section{Introduction/Background}

Dry needling $(\mathrm{DN})$ is a subcutaneous needle insertion technique using a fine, solid needle without anesthetic or injection [1]. DN can be distinguished from acupuncture, which although applied with a solid filiform needle, uses Traditional Chinese Medicine principles, [2] and also from other techniques that use injectable substances through a hypodermic needle [3]. When DN is combined with electrical stimulation of various frequencies and intensities, certain pain modulating neurotransmitters may be released [4-6]. DN has been further defined by the American Physical Therapy Association as “... a skilled intervention that uses a thin filiform needle to penetrate the skin and stimulate underlying myofascial trigger points, muscular and connective tissues for the management of neuromusculoskeletal pain and movement impairments. $\mathrm{DN}$ is a technique used to treat dysfunctions in skeletal muscle, fascia, connective tissue and diminish persistent peripheral nociceptive input, and reduce or restore impairments of body structure and function leading to improved activity and participation" [7].

Legge [8] observed that DN began when practitioners and researchers were looking for ways to treat muscular pain at tender points with injections and found that even without injections, DN could provide relief. Legge concluded that currently some practitioners and researchers specifically use DN solely to treat myofascial $\operatorname{TrP}$, and that the majority of literature on DN refers to its use in the treatment of myofascial TrP. In the same article, Legge also pointed out that other practitioners support a larger use of DN for ligamentous, tendinous, articular and scar tissue disorders as well.

Current literature appears to support DN for the treatment of myofascial pain due to TrP [9]. Dommerholt postulated DN may help limit nociception from TrP and discussed the possible physiological mechanisms of pain relief with DN [4]. Dry needling in neck and back pain treatment has been evaluated previously. Ong [10] found no difference between DN and lidocaine injection for relief of neck and shoulder pain. In a systematic review and meta-analysis on the effectiveness of DN for low back pain (LBP) by $\mathrm{Hu}$ [11], DN was found more effective for reducing pain and disability than acupuncture, sham acupuncture, or other treatment. However, the effectiveness was equal to that of acupuncture at long term follow-up. $\mathrm{Hu}$ also concluded that the current evidence does not support the efficacy and safety of DN for LBP. A meta-analysis by Gattie [12] concluded there was very low to moderate evidence that DN to TrP yielded significant effect on functional outcomes in the short term, but was not better than other treatments in the long term.

A systematic review (SR) by Liu L et al. in 2015 [13] studied the effectiveness of DN or acupuncture versus wet needling with lidocaine injectate for both neck and shoulder pain and concluded that even though DN could be recommended for TrP in NP and shoulder pain, wet needling with lidocaine was more effective than DN in the medium term. Liu et al. included shoulder pain that could be from local sources (shoulder stuctures) that are not specifically a SRD and also included acupuncture, which we specifically excluded. Their conclusions may differ from future SR of studies looking at DN only for NP due to SRD only. Another SR by Liu et al. [14] looked at 11 RCTs using DN for LBP and found moderate evidence to recommend $\mathrm{DN}$ for $\mathrm{TrP}$ associated with LBP when used with other therapies. They concluded it was unclear whether DN was superior to other treatments for improving functional disability. EspejoAntunez et al. [15] searched DN for myofascial trigger points and identified 90 articles, and then systematically reviewed 15 articles in areas ranging from the spine, knee and TMJ. They concluded that although there was some evidence to support use of $\mathrm{DN}$ for $\mathrm{TrP}$ for short term pain relief, further RCT using standardized procedures to identify TrP and apply DN are needed.

As mentioned above, the American Physical Therapy Association states DN can be used for the management of neuromusculoskeletal pain and movement impairments. Although DN treatment appears widely accepted for $\mathrm{TrP}$, it is unclear which other painful conditions and movement impairments it is best suited for. For example, the use of DN for other painful conditions due to SRD as described by Murphy [16, 17] has not been summarized.

SRD that are not secondary to serious pathology have been described by Murphy as having four major pain generators. These are: disc derangement, radiculopathy, joint dysfunction and myofascial trigger points [16, 17]. Pain generators may occur alone or in any combination, and can often be differentiated through history and physical examinations. According to Murphy, TrP are common sources of axial and referred pain but typically form in response to pain from other sources, and once the primary pain source is relieved, the TrP will often resolve. However, in some cases, they persist and should be treated as well ([16], p. 247). Treatments recommended for TrP in Murphy's Clinical Reasoning in Spine Pain (CRISP) protocols include manual pressure release techniques (digital or instrument assisted pressure), muscle lengthening techniques (i.e. post-isometric relaxation) and combined release and lengthening ([16], p., 248-9). Medical treatments available include oral and injected anesthetics, steroidal and non-steroidal anti-inflammatories, or botulinum toxin injection [18]. Murphy does not discuss DN as a potential treatment for TrP or other SRD.

The available meta-analyses (MA) and SR [10-15] only looked at specific subsets of data or were relatively 
generic in their inclusion criteria. Many of the papers discussed in this scoping review would not have been included in available systematic reviews or may have used DN treatment on disorders not specifically defined as SRD.

Therefore we sought to perform a scoping review to describe the DN research in the context of its use in all SRD, including spine-region $\operatorname{TrP}$. Scoping reviews describe the extent of current literature on a subject and help to expose gaps that could be targets of potential future research. This scoping review seeks to identify research from case reports $(\mathrm{CR})$, case series $(\mathrm{CS})$, clinical trials $(\mathrm{CT})$ and randomized controlled trials (RCT) published on DN treatment for patients with SRD diagnoses and to make evident where research is plentiful as well as lacking. We hope to add to the discussion of the role of DN in neuromusculoskeletal treatment to specifically include SRD. This review therefore will categorize which muscles or other structures have been used as treatment sites, whether treatment was directed at specific myofascial $\operatorname{Tr} P$ only, or other named structures, the outcome measures studied and whether DN was considered effective.

\section{Methods}

A scoping review of the literature on DN for SRD was conducted following the methodological framework as first outlined by Arksey et al. [19] and further refined by Levac et al. [20] and Peters et al. [21]. This framework, consisting of the five steps below, aims to elucidate the current state of the literature on the topic and highlight any gaps in the knowledge base.

\section{Step 1. Identifying the research question}

What is the state of the current primary research literature on DN for patients with SRD? Specifically, which SRD diagnoses or conditions have been studied, and which specific structures have been treated in these studies? In addition, how many treatments have been used in the studies? Was DN the sole intervention or was it combined with other interventions, and finally, what outcome tools were used to determine effectiveness?

\section{Step 2. Identifying relevant studies}

Two reviewers initially conducted independent searches in PubMed, AMED, CINAHL and Cochrane Library for relevant publications from 1990 through August 7, 2018, when the search period ended. National Library of Medicine Medical Subject Headings were created by combining "dry needling" (only, to limit the search to exclude acupuncture or other needle techniques), with terms that reflect conditions considered to be SRD. These SRD terms include general ones such as neck pain and back pain, regional spine terms such as cervical, thoracic, or lumbar, as well as pain-generating structures including myofascial, articular, nerve or disc. Using the subject heading terms listed in Table 1, each reviewer independently compiled a primary list of prospective studies to be reviewed. An additional search of PubMed for papers with the subject "dry needling AND trigger point" was done in order to capture any studies missed in the initial search strategy. Another search was performed in PubMed with the term "dry needling", and papers from before 1990 were selected. The grey literature was independently searched utilizing Open Grey, Clinicaltrials.gov, Canadian Agency for Drugs and Technologies in Health, New York Academy of Medicine Grey Literature Report, University of York Centre for Reviews and Dissemination, National Technical Information Service and the U.S. Government Documents (Table 2). The reference lists of all included studies were reviewed to ensure a complete search was performed.

\section{Step 3. Study selection}

Each author independently retrieved papers from the primary list and eliminated titles as per the inclusion and exclusion criteria (as listed in Table 3). The authors compared results and any discrepancies were mediated through discussion. Each author then independently reviewed abstracts and further eliminated papers according to the inclusion/exclusion criteria.

\section{Step 4. Charting the data}

The inclusion and exclusion criteria were reapplied to the selected full papers and the following data were collected: author, title, year of publication, study design, number of study subjects and spinal region. Other information was collected including the conditions treated with DN (and specific muscles when described), purpose of study, duration of study, intervention(s), comparison(s) as well as outcome measures used. Each study's reported results were also collected.

Table 1 Search terms

\begin{tabular}{ll}
\hline Cervical region & Thoraco-lumbar-pelvic region \\
\hline DN and neck pain & $\begin{array}{l}\text { DN AND (back pain OR sacroiliac } \\
\text { OR spine) }\end{array}$ \\
DN and headache & DN AND disc AND (lumbar OR thoracic) \\
$\begin{array}{l}\text { DN AND nerve AND } \\
\text { (cervical OR neck) }\end{array}$ & DN AND (neur* OR sciatic*) \\
DN AND neur* & DN AND (joint OR articul*) \\
DN AND (joint or articul*) & DN AND disc \\
DN AND disc & DN AND paravertebral \\
DN AND myofascial & DN AND (thor* OR lumb* OR sacr* \\
ON glut*) & DN AND trigger point \\
DN AND cervic* muscle & \\
DN AND trigger point & \\
\hline
\end{tabular}


Table 2 Grey literature sources and results

\begin{tabular}{llll}
\hline Database & $\begin{array}{l}\text { Dry needling } \\
\text { AND spine hits }\end{array}$ & Met Inclusion & Duplicates \\
\hline Open Grey & 1 & 0 & 0 \\
ClinicalTrials.gov & 2 & 0 & 0 \\
CADTH & 8 & 1 & 1 \\
NYAM & 0 & 0 & 0 \\
CRD - York & 20 & 6 & 6 \\
U.S. Gov Docs & 0 & 0 & 0 \\
Total & $\mathbf{3 1}$ & $\mathbf{7}$ & $\mathbf{7}$ \\
\hline
\end{tabular}

\section{Step 5. Summarizing and reporting the results}

Studies on DN for SRD were recorded on a Microsoft Excel $^{\circ}$ spreadsheet separately for the cervical (C) and thoracolumbar-pelvic (TLP) regions. Study types, including CR, CS, CT and RCT are presented in Table 4 as totals and percentages. The condition(s) treated are presented in Table 5 . The muscle(s) treated, when specified, are presented in Tables 6 and 7. The number of treatments provided to subjects in each study can be found in Table 8 . Table 9 presents the number of studies in which DN was the only treatment as well as those

Table 3 Inclusion and exclusion criteria

\begin{tabular}{ll}
\hline Inclusion Criteria & Cervical region: posterior from the superior \\
nuchal line and mastoid to the spine of the \\
scapula, anteriorly from the inferior border \\
of the mandible to clavicle, and laterally to \\
the acromion of the scapula. Pain and/or \\
treatment within region defined above. \\
Thoraco-lumbar-pelvic (TLP) region: \\
posteriorly from the inferior border of \\
the spine of the scapula to the coccyx, \\
laterally to the mid-axillary line, inferiorly \\
to the horizontal lower margin of the \\
buttock at its junction with the thigh \\
(gluteal fold). Pain and/or treatment \\
within the region defined above. \\
Dry Needling not specified in title or \\
abstract \\
Pathological conditions, non-mechanical \\
pain or secondary to other pathology \\
Not English language \\
Full paper available through university \\
library \\
Post-August 7, 2018 \\
Study types: non-experimental designs, \\
narrative reviews, systematic reviews, \\
meta analyses, protocols, reports of \\
complications only, editorials, \\
commentaries, patient brochures, \\
poster summaries, letters to the editor \\
Methodologies: non-human subjects, \\
asymptomatic patients only, physiological \\
responses only, treatment effects not \\
reported, side-effects only reported \\
without other clinical effects \\
\end{tabular}

Table 4 Study type, number of papers (percent of total) per region

\begin{tabular}{lll}
\hline & Cervical & TLP \\
\hline $\begin{array}{l}\text { Randomized Controlled } \\
\text { Trial (RCT) }\end{array}$ & $37(60)$ & $10(45.45)$ \\
Case Report (CR) & $6(10.91)$ & $4(18.18)$ \\
Clinical Trial (CT) & $10(18.18)$ & $5(22.73)$ \\
Case Series (CS) & $2(3.64)$ & $3(13.64)$ \\
Total & $\begin{array}{l}\mathbf{5 5}(\mathbf{7 1 . 4 3} \% \\
\text { of studies) }\end{array}$ & $\begin{array}{l}\mathbf{2 2}(\mathbf{2 8 . 5 7 \%} \\
\text { of studies) }\end{array}$ \\
\hline
\end{tabular}

that combined $\mathrm{DN}$ with another treatment $(\mathrm{DN}+)$. The outcomes measured (such as VAS, ROM, patient reported outcomes) and the outcomes improved following treatment are presented in Table 10. These quantitative results were analyzed to reveal trends and gaps in the research for DN in SRD.

Table 5 Number of studies describing treatment per condition per region (percent of total)

\begin{tabular}{|c|c|c|}
\hline & $\begin{array}{l}\text { Cervical } \\
\text { (55 studies) }\end{array}$ & $\begin{array}{l}\text { TLP (22 } \\
\text { studies) }\end{array}$ \\
\hline myofascial trigger points & $29(43.28)$ & $10(31.25)$ \\
\hline myofascial pain & $14(20.9)$ & $3(9.37)$ \\
\hline neck pain & $10(14.93)$ & $(3.12)$ \\
\hline cervicogenic headache $(\mathrm{HA})$ & $3(4.48)$ & \\
\hline tension-type HA & $1(1.49)$ & \\
\hline HA (type not specified) & $1(1.49)$ & \\
\hline occipital neuralgia & $1(1.49)$ & \\
\hline dizziness & $1(1.49)$ & \\
\hline wry neck & $1(1.49)$ & \\
\hline chronic whiplash associated disorder & $1(1.49)$ & \\
\hline cervical radiculopathy & $1(1.49)$ & \\
\hline reduced cervical mobility & $1(1.49)$ & \\
\hline shoulder pain & $1(1.49)$ & \\
\hline back pain & $1(1.49)$ & \\
\hline muscle pain & $1(1.49)$ & \\
\hline chronic low back pain (LBP) & & $6(18.75)$ \\
\hline mechanical LBP & & $3(9.37)$ \\
\hline thoracic pain & & $2(6.25)$ \\
\hline discogenic LBP with radiation & & $1(3.12)$ \\
\hline lumbar herniated disc & & $1(3.12)$ \\
\hline posterior thigh pain & & $1(3.12)$ \\
\hline lumbar spinal stenosis & & $1(3.12)$ \\
\hline sacroiliac and lumbar pain & & $1(3.12)$ \\
\hline ankylosing spondylitis & & $1(3.12)$ \\
\hline fibromyalgia & & $1(3.12)$ \\
\hline Total conditions treated & 67 & 32 \\
\hline
\end{tabular}

Some studies included treatment for multiple conditions 
Table 6 Number of studies describing structure treated in the cervical region (percent of total)

\begin{tabular}{|c|c|}
\hline & Cervical \\
\hline Upper trapezius & $35(29.91)$ \\
\hline Trapezius (site unspecified) & $11(9.40)$ \\
\hline Levator scapulae & $10(8.55)$ \\
\hline Suboccipital muscles & $(5.13)$ \\
\hline Cervical paravertebrals & $(4.27)$ \\
\hline Cervical multifidi & $4(3.42)$ \\
\hline Semispinalis capitis & $4(3.42)$ \\
\hline Middle trapezius & $3(2.56)$ \\
\hline Supraspinatus & $5(4.27)$ \\
\hline Splenius capitis & $4(3.42)$ \\
\hline Infraspinatus & $5(4.27)$ \\
\hline Sternocleidomastoid (SCM) & $3(2.56)$ \\
\hline Posterior cervical (site unspecified) & $2(1.71)$ \\
\hline Masseter & $2(1.71)$ \\
\hline Temporalis & $2(1.71)$ \\
\hline Spinalis capitis & $1(0.85)$ \\
\hline Clavicular (SCM) & $1(0.85)$ \\
\hline Splenius cervicis & $1(0.85)$ \\
\hline Scalenes & $2(1.71)$ \\
\hline Rhomboid & $2(1.71)$ \\
\hline Teres minor & $1(0.85)$ \\
\hline Thoracic multifidi & $1(0.85)$ \\
\hline Posterior arch C1 & $1(0.85)$ \\
\hline Spinous process $\mathrm{C} 2$ & $1(0.85)$ \\
\hline Acromioclavicular joint & $1(0.85)$ \\
\hline Unspecified cervical spinous processes & $1(0.85)$ \\
\hline Other miscellaneous non-muscular Structures & $1(0.85)$ \\
\hline Platysma & $1(0.85)$ \\
\hline Unknown & $1(0.85)$ \\
\hline Total conditions treated & 117 \\
\hline
\end{tabular}

Some studies included treatment for multiple muscles

\section{Results}

\section{Relevant studies identified and collected}

Figure 1 presents the PRISMA flow diagram [22] illustrating the records identified and those that were excluded and included during the initial literature search. There were 933 titles screened in the $C$ region and 436 in the TLP region. From the initial titles screened, 302 and 79 abstracts were reviewed from the C and TLP regions, respectively. Forty-eight studies were included in the $\mathrm{C}$ region and 16 in the TLP region for further analysis. The $\mathrm{MeSH}$ terms used during the literature search for the $C$ region and TLP region are shown in Table 1. This search was completed in PubMed, AMED, CINAHL and the Cochrane Library. A secondary search
Table 7 Number of studies describing structure treated in TLP region (percent of total)

\begin{tabular}{|c|c|}
\hline & TLP \\
\hline lumbar multifidi & $6(8.45)$ \\
\hline quadratus lumborum & $9(12.68)$ \\
\hline gluteus medius & $8(11.27)$ \\
\hline gluteus maximus & $5(7.04)$ \\
\hline thoracic multifidi & $2(2.82)$ \\
\hline thoracic paravertebrals & $3(4.23)$ \\
\hline paravertebrals (unspecified) & $2(2.82)$ \\
\hline piriformis & $4(5.64)$ \\
\hline lower trapezius & $2(2.82)$ \\
\hline latissmus dorsi & $2(2.82)$ \\
\hline thoraco-lumbar iliocostalis & $2(2.82)$ \\
\hline lumbar erector spinae & $2(2.82)$ \\
\hline sacral multifidi & $1(1.41)$ \\
\hline multifidi (unspecified) & $1(1.41)$ \\
\hline psoas major & $1(1.41)$ \\
\hline iliopsoas & $2(2.82)$ \\
\hline gluteus minimus & $3(4.23)$ \\
\hline gluteal muscles & $1(1.41)$ \\
\hline tensor fasciae latae & $2(2.82)$ \\
\hline hamstrings & $1(1.41)$ \\
\hline rectus femoris & $2(2.82)$ \\
\hline gastrocnemius & $1(1.41)$ \\
\hline iliolumbar ${ }^{a}$ & $1(1.41)$ \\
\hline transforaminal epidural & $1(1.41)$ \\
\hline lumbar paravertebrals & $1(1.41)$ \\
\hline pelvic ligaments (unspecified) & $1(1.41)$ \\
\hline ribs & $1(1.41)$ \\
\hline ischial tuberosity & $1(1.41)$ \\
\hline unspecified thoracic or lumbar spinous processes & $1(1.41)$ \\
\hline miscellaneous non-muscular structures & $1(1.41)$ \\
\hline $\begin{array}{l}\text { segmental myotomal points throughout the spine } \\
\text { and lower extremity }\end{array}$ & $1(1.41)$ \\
\hline Total conditions treated & 71 \\
\hline
\end{tabular}

Some studies included treatment for multiple muscles

ailiolumbar specified as muscle treated

of PubMed for "dry needling AND trigger point" yielded 294 total hits, of which 288 were excluded. Five studies involved treatment in the cervical region [23-27] and three in the thoraco-lumbo-pelvic region $[23,25,28]$. Two studies included DN treatments in both the cervical and TLP regions [23, 25]. Furthermore, an additional search for pre-1990 papers using PubMed and the term "dry needling" yielded 9 hits, of which four met criteria. Two papers were included that had treatment in the cervical region $[29,30]$ and 
Table 8 Number of treatments per region

\begin{tabular}{lll}
\hline & Cervical & TLP \\
\hline 1 & 23 & 8 \\
2 & 4 & 2 \\
3 & 9 & 2 \\
4 & 8 & 2 \\
5 & 1 & 2 \\
6 & 3 & 1 \\
7 & 0 & 0 \\
8 & 3 & 1 \\
9 & 1 & 0 \\
$13+$ & 0 & 1 \\
variable & 1 & 1 \\
unknown & 1 & 2 \\
Total & $\mathbf{5 5}$ & $\mathbf{2 2}$ \\
\hline
\end{tabular}

three in the TLP region [30-32], with one providing treatment in both regions [30]. Table 2 depicts the grey literature search, the search term and databases searched, as well as the number of studies which met inclusion criteria. All studies that met inclusion criteria (1 from CADTH and 6 from CRD-York) were duplicates already found during the original database search. The inclusion and exclusion criteria utilized during the literature search are presented in Table 3. Additional file 1, ("Complete data as Tables 4.1 and 4.2") contains each selected study's reference number [33-95], lead author, and article title that are displayed in Tables 4.1 (Complete data, Cervical region) and 4.2 (Complete data, TLP region).

\section{Selected study parameters}

Additional file 1 (Tables 4.1 and 4.2) also include research methodology, experimental subject population (n), study parameters, condition(s) treated with $\mathrm{DN}$, any comparison intervention, the duration of study with number of treatment sessions, muscle(s) treated, whether DN was used alone, treatment in addition to DN, outcome tool(s) used, outcomes improved with $\mathrm{DN}$, results and implications, whether $\mathrm{DN}$ was superior to other intervention, and additional comments.

Table 9 Number of studies with DN as sole intervention versus DN used with another intervention (DN+)

\begin{tabular}{lll}
\hline & Cervical (55 studies) & TLP (22 studies) \\
\hline $\mathrm{DN}$ & 34 & 10 \\
$\mathrm{DN}+$ & 24 & 13 \\
Total & $\mathbf{5 8}$ & $\mathbf{2 3}$ \\
\hline
\end{tabular}

Some studies had multiple treatment arms

\section{Study design}

Table 4 presents the number of studies and percent of total studies in the categories of RCT, CT, CR, and CS in both $\mathrm{C}$ and TLP regions. Fifty-five studies were found in the $\mathrm{C}$ region $(71.43 \%)$ and 22 in the TLP region (28.57\%). Most studies were RCT (60\% in C, $45.45 \%$ in TLP) and CT (18.18\% in C, $22.78 \%$ in TLP).

\section{Intervention characteristics}

Table 5 depicts the conditions treated per region as described in each study. A few studies investigated DN for multiple conditions. Treatment was provided for specific diagnoses as well as relatively non-specific conditions such as neck pain (NP), shoulder pain, back pain, muscle pain, thoracic pain, posterior thigh pain and sacroiliac plus lumbar pain.

In the $55 \mathrm{C}$ region studies there were a total of 67 conditions treated, and in the 22 TLP region studies, 32 conditions were treated. The most commonly treated condition was $\operatorname{TrP}$ for both the $\mathrm{C}$ and TLP regions. There were 29 studies describing treatment for $\operatorname{TrP}$ in the $C$ region (43.28\%) and in the TLP region there were $10(31.25 \%)$. The condition "myofascial pain" was studied in an additional $14(20.9 \%)$ in the $C$ region and 3 (9.37\%) in the TLP region. Neck pain was described as the condition treated in $10(14.93 \%)$ of the $\mathrm{C}$ region studies. One study applied DN to the $\mathrm{C}$ region for "back pain." In the $\mathrm{C}$ region, cervicogenic headache (CGH) was described as the condition treated in $3(4.48 \%)$ of studies, while tension-type headache (TTH), unspecified headache (HA), and occipital neuralgia were the target condition in one study each. Combining CGH, TTH, unspecified HA and occipital neuralgia, there were six studies (10.91\%) on DN for all HA conditions.

In the TLP region, the most common condition treated was chronic LBP, found in 6 studies (18.75\%), with mechanical LBP next at $3(9.37 \%)$ and thoracic pain in 2 (6.25\%). Discogenic LBP with radiation, lumbar herniated disc, posterior thigh pain and lumbar spinal stenosis were the targets of $\mathrm{DN}$ in one study each. One study applied DN to the TLP region for NP.

The particular structures treated with $\mathrm{DN}$ in the $\mathrm{C}$ region, when specified, are listed in Table 6. Most treatments in the $\mathrm{C}$ region were directed to muscle except for one study that did not specify the muscle treated, and a study that included DN treatment of bone or other non-muscular structures [30]. Of the $55 \mathrm{C}$ region papers, $\mathrm{DN}$ was provided to 23 different muscles. There were a total of 117 treatments in the $C$ region. The upper trapezius, trapezius, and middle trapezius combined for 49 of 117 total treatment sites mentioned (41.88\%). Many studies performed treatments directed to multiple muscles. 
Table 10 Outcome tools used and improved with DN

\begin{tabular}{|c|c|c|c|c|}
\hline & Cervical $(55 \mathrm{~s}$ & & TLP (22 stud & \\
\hline & No. studies & No. improved with DNa & No. studies & No. improved with $\mathrm{DN}^{\mathrm{a}}$ \\
\hline Visual Analog Scale (VAS) & 35 & 33 & 11 & 11 \\
\hline Pain Pressure Threshold (PPT) & 31 & 28 & 7 & 7 \\
\hline Range of motion (ROM) & 27 & 24 & 4 & 3 \\
\hline Short Form-36 (SF-36) & 8 & 7 & 1 & 1 \\
\hline Numeric Pain Rating Scale (NPRS) & 8 & 8 & 6 & 6 \\
\hline Beck Depression Index (BDI) & 4 & 3 & 2 & 1 \\
\hline Oswestry Disability Index (ODI) & 2 & 2 & 8 & 8 \\
\hline Self-rated improvement scale & 1 & 0 & 1 & 1 \\
\hline Patient reported pain & 2 & 2 & 2 & 2 \\
\hline SF-12 Physical & 1 & 1 & 1 & 1 \\
\hline SF-12 Mental & 1 & 1 & 1 & 1 \\
\hline Neck Disability Index (NDI) & 13 & 13 & & \\
\hline Medication use & 5 & 5 & 2 & 2 \\
\hline Nottingham Health Profile (NHP) & 3 & 2 & & \\
\hline Dizziness Handicap Inventory (DHI) & 2 & 2 & & \\
\hline Headache index & 2 & 2 & & \\
\hline Symptom Severity Index (SSI) & 2 & 2 & & \\
\hline Verbal Pain Scale & 2 & 2 & & \\
\hline Brief Pain Inventory (BPI) & 2 & 1 & & \\
\hline Profile of Mood States (POMS) & 2 & 1 & & \\
\hline Beck Anxiety Index (BAI) & 1 & 1 & & \\
\hline Disabilities of the Arm, Shoulder and Hand (DASH) & 1 & 1 & & \\
\hline Geriatric Depression Scale Short Form (GDS-SF) & 1 & 1 & & \\
\hline Neck Pain Disability Index (NPDS) & 1 & 1 & & \\
\hline Northwick Park Neck Pain Questionnaire (Spanish) & 1 & 1 & & \\
\hline Nottingham Extended Activities of Daily Living Scale (NEADLS) & 1 & 1 & & \\
\hline Quadruple Visual Analog Scale (QVAS) & 1 & 1 & & \\
\hline Sympathetic skin response $(\mathrm{SSR})^{\mathrm{b}}$ & 1 & 1 & & \\
\hline Assessment of change (11 point) & 1 & 0 & & \\
\hline Fall Index & 1 & 0 & & \\
\hline Hamilton Anxiety and Depression Inventory & 1 & 0 & & \\
\hline Global Rating of Change (GRoC) & & & 4 & 3 \\
\hline Tampa Scale for Kinesiophobia (TSK) & & & 2 & 2 \\
\hline US-imaging of multifidi & & & 2 & 2 \\
\hline Functional Rating Index & & & 1 & 1 \\
\hline McGill Pain Questionnaire (MPQ) & & & 1 & 1 \\
\hline Northwick Park Neck Pain Questionnaire & & & 1 & 1 \\
\hline Patient specific functional scale & & & 1 & 1 \\
\hline Roland-Morris Disability Questionnaire (RMQ) & & & 1 & 1 \\
\hline Sleep quality & 2 & 2 & 2 & 2 \\
\hline Straight Leg Raise Test (SLR) & & & 1 & 0 \\
\hline 4 point patient subjective improvement scale & & & 1 & 1 \\
\hline Total (percent improved) & 166 & 149 (89.76\%) & 63 & 58 (92.06\%) \\
\hline
\end{tabular}

Some studies used more than one outcome measure

aimprovement as per author

${ }^{b}$ physiological response 


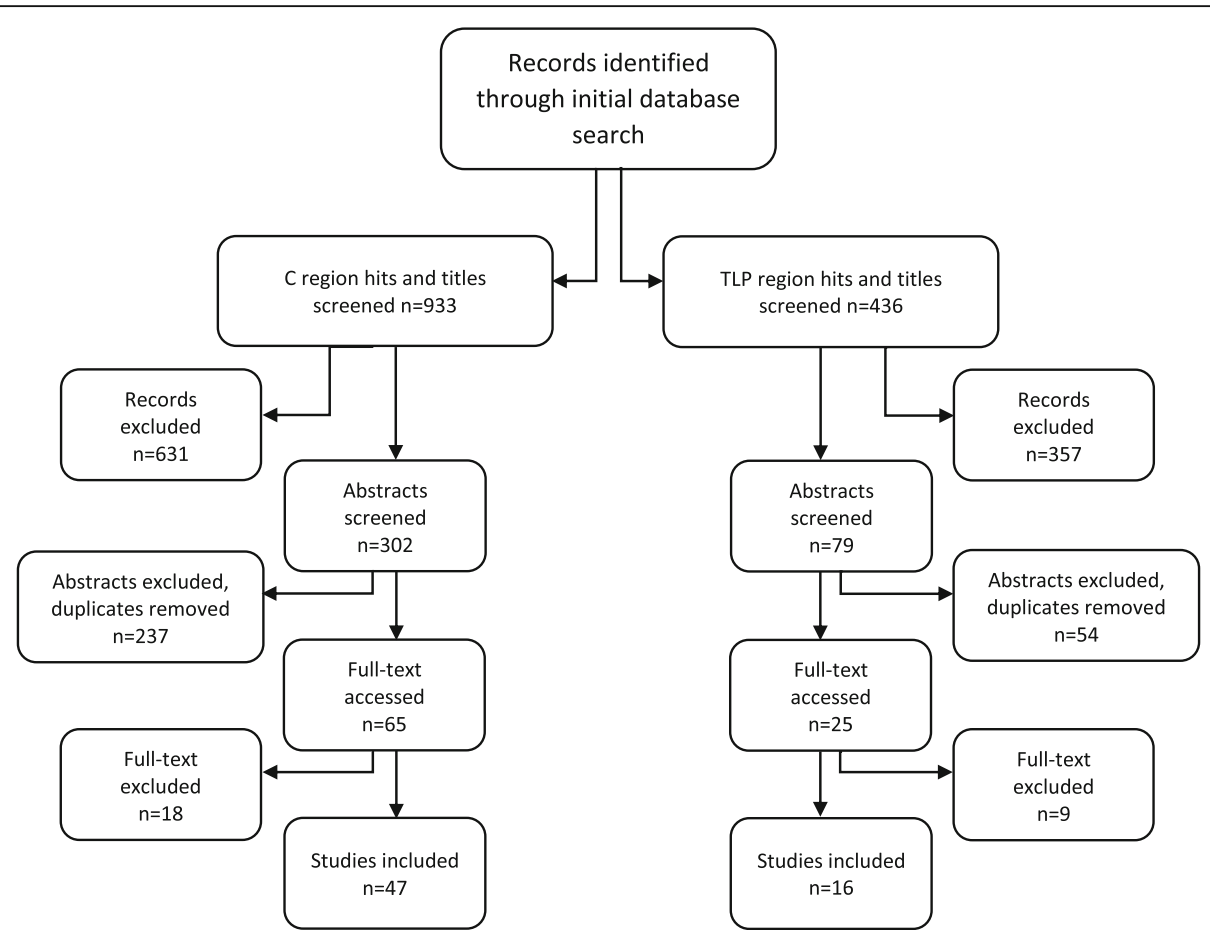

Fig. 1 PRISMA flow diagram illustrating the records identified and those that were excluded and included during the initial literature search

Table 7 presents the 31 different structures treated with DN in the TLP region. There were a total of 64 muscle treatment sites, since again, some studies treated multiple muscles. The "iliolumbar" muscle was described as the target of DN in one study [94]. One study investigated a site that was not muscle, namely the effects of transforaminal epidural $\mathrm{DN}$ on lumbar spinal stenosis [80]. The quadratus lumborum, gluteus medius and lumbar multifidi were the most commonly treated muscles in the TLP region. Some muscles were not specifically described, such as "gluteal muscles" and "hamstrings." The exact sites were not specified in two studies of DN treatment to paravertebral muscles $[93,95]$ and in one study of $\mathrm{DN}$ to multifidi [87]. Treatment to multifidi (lumbar, thoracic, sacral and unspecified), comprise 10 of the 64 TLP region treatment sites mentioned (15.62\%).

Table 8 shows the number of DN treatments, per region, as described in each study's Methods section. In the $\mathrm{C}$ region, there was just one treatment provided in 23 studies (41.82\%), 2-6 treatments in 25 (45.45\%), 7-9 treatments in 4 studies $(7.27 \%)$ and none had 13 or more. One study varied treatment numbers per study arm and one did not describe the number of DN treatments provided. For the TLP region, one DN treatment was provided in 8 of the 22 total studies (36.36\%), 2-6 in 9 (40.9\%), one had between 7 and 9 treatments, and one had more than 13 treatments.

Table 9 provides the number of studies with $\mathrm{DN}$ as the sole intervention versus $\mathrm{DN}$ used with another intervention. There were 58 total investigations in the $\mathrm{C}$ region and 23 in the TLP region. About half (54.32\%) of experimental designs had DN as the sole intervention.

\section{Outcomes measures and results reported}

Table 10 shows the number of studies using different outcome assessment measures in the C and TLP regions along with those demonstrating improvement in outcome post $\mathrm{DN}$ as described by the study authors. For both the $C$ and TLP regions, Visual Analogue Scale (VAS), Pressure Pain Threshold (PPT) and Range of Motion (ROM) were the most common outcomes. The most commonly used $\mathrm{C}$ region-specific outcome measure used was Neck Disability Index (NDI); Oswestry Disability Index (ODI) was the most common outcome measure in the TLP region. Most studies reported substantial improvement post $\mathrm{DN}$ in the measures studied. Improvement was reported in $89.76 \%$ of $\mathrm{C}$ region outcomes and $92.06 \%$ of the TLP region outcomes.

\section{Implications}

\section{Spinal regions studied}

It is estimated that $80 \%$ of the population will experience at least one episode of LBP [96]. Back pain, defined as below the 12th rib and not including the upper and mid-back [97], is the single leading cause of disability and imposes a very high economic burden worldwide. Neck pain lifetime prevalence is estimated at about 50\% [98]. Although the incidence of LBP is greater than that 
of NP, only $28.57 \%$ of the included studies investigated DN for the TLP region, compared to $71.43 \%$ from the C region. More research should be done to establish the clinical relevance of DN for SRD below the $\mathrm{C}$ region, given the fact that LBP has greater population impact.

\section{Conditions studied}

DN was often applied to muscle or myofascia regardless of the diagnosis. Most studies inserted the needle into muscle with exceptions being transforaminal epidural DN [80], pelvic ligaments and various bony landmarks, such as spinous processes [30]. Non-specific terminology was often used to describe conditions treated. For example, in some cases, non-specific diagnoses such as NP or chronic LBP were made and treatment rendered without a specific pain generator described. In addition, there were examples where the methodology did not specify the exact needle insertion location, only stating the general area or large muscle region, such as posterior cervical muscles, trapezius, paravertebral muscles and multifidi (unspecified) as shown in Tables 6 and 7. The exact sites of DN insertion were not included in all studies. Increased treatment site specificity may provide further clinical insight in future research.

Myofascial pain or $\operatorname{TrP}$ were the most commonly treated conditions in each region comprising $64.18 \%$ of the studies in the $\mathrm{C}$ region and $40.62 \%$ for the TLP region. The American Physical Therapy Association's Educational Resource Paper on Dry Needling [7] defines DN as an intervention for neuromusculoskeletal pain and movement impairments such as $\operatorname{TrP}$ and other muscular and connective tissue disorders. A few studies, as shown in Table 5, evaluated DN for non-myofascial conditions. The APTA also states DN is a treatment option to reduce or restore impairments of body structure and function. Since we found very few studies investigating nonmyofascial conditions, it is unclear what is meant by this recommendation. Only two studies in the $\mathrm{C}$ region specifically evaluated nerve-related pain (cervical radiculopathy, occipital neuralgia) and only two studies evaluated disc-related conditions (discogenic LBP with radiation, lumbar herniated disc). Murphy suggests that $\operatorname{TrP}$ are often secondary to other SRD [16]. It is unknown whether DN creates an important and lasting patient response if applied specifically to articular, disc or nerve structures or if DN is only effective when applied to $\operatorname{TrP}$ secondary to other conditions. Further investigation into the effects of DN applied directly to nonmyofascial pain generators may provide further clinical insights.

\section{Treatment parameters}

As seen in Table 8, most studies applied just one treatment before assessing the outcome. One could question if this mirrors clinical practice. Is it more common to apply multiple treatments, and at what frequency? The relative effectiveness may vary with different treatment numbers, frequency or duration. Specific investigation of optimal frequency and duration could be helpful for clinical practice. We found no studies that specifically investigated variable treatment numbers and frequencies for a given SRD. This is supported by Dunning et al. [1] who state "the optimal frequency, duration, and intensity of dry needling has yet to be determined for many neuromusculoskeletal conditions." Future research may help determine a standard clinical treatment practice for different conditions.

\section{Interventions (DN alone or in combination)}

Most studies looked at DN as a sole intervention while fewer had DN plus another intervention in the experimental design. It would be helpful to know if clinical outcomes are improved when DN is used as a component in a treatment plan consisting of multiple procedures and modalities. Regarding DN being used as a sole intervention in SRDs, it is unclear if this comports with common clinical practice. Future research that compares DN alone along with DN plus other treatments may help determine optimal treatment protocols.

\section{Outcomes}

It appears that DN is beneficial for a number of conditions, as shown in Table 10. Most studies in the $\mathrm{C}$ region used pain scale ratings such as VAS, NPRS, verbal pain scale and QVAS. Also popular were PPT and ROM. In fact, $62.65 \%$ included pain scales, PPT and ROM within the $55 \mathrm{C}$ region studies. The most popular functional outcome tools in the $\mathrm{C}$ region were the NDI, followed by the SF-36. Although studies investigating only physiological responses were excluded, one study used sympathetic skin response along with other outcomes [61]. Some outcomes such as NHP, BDI and DHI were used in four studies or fewer. In the TLP region VAS, PPT, ROM and NPRS accounted for $44.44 \%$ of the investigated outcomes. The most popular functional indices in the TLP region were ODI and GRoC, which combined for $19.05 \%$ of outcomes studied. As in the C region, there were other outcome measures used in a small number of studies such as BDI, MPQ, RMQ and TSK amongst others. Two studies looked at ultrasound imaging of the multifidi along with other outcomes studied $[84,86]$. It is unknown whether some treatment effects of DN for SRD may be best demonstrated with particular functional indices.

Although scoping reviews do not critically appraise the quality of the literature, it appears most of the 
cited authors concluded that DN contributes to improved outcomes in many SRD. These outcomes were demonstrated regardless of diagnosis, number of treatments or patient population. Future studies that look at strict diagnostic and inclusion criteria, detailed treatment methods and most applicable outcome measures would be helpful in filling the gaps in the literature as it relates to the effectiveness of $\mathrm{DN}$ for SRD.

\section{Limitations}

By limiting our title and abstract searches to DN (only), the authors recognize that papers describing other needle-based techniques that are not specifically called DN were excluded. Such studies may have data reported that could help in the overall understanding of the effects of various needling principles and techniques in treatment of SRD. In our understanding of SRD according to Murphy, there may be some conditions that were not included. However, studies investigating treatment for conditions that appeared to be emanating from the spine, and not secondary to a serious pathology such as cancer or infection, were included to the best of our ability. Furthermore, we limited our search to English language only, thus excluding studies in other languages that may have been sources of additional data.

\section{Conclusions}

This scoping review demonstrates that for SRD, DN was primarily applied to myofascial structures for myofascial pain or $\mathrm{TrP}$ diagnoses, although other non-myofascial and non-specific diagnoses were also treated. Dry needling treatment to non-myofascial sites has been investigated primarily in extremity conditions [99]. There is currently little research on DN that specifically targets other SRD pain generators [16] including nerve roots, disc, tendons, ligaments, periosteum, scar tissue or fascia in SRD. It appears that many outcomes are improved regardless of diagnosis or treatment parameters. Most of the included studies applied just one treatment before assessing an outcome, which may not reflect common clinical practice. Further research is warranted to determine optimal treatment duration and frequency for SRD using DN. Most studies looked at DN as the sole intervention. It is unclear whether $\mathrm{DN}$ as a sole intervention or in conjunction with other treatments provides the best patient outcomes. The most commonly studied outcomes were pain rating scales, PPT and ROM while other patient reported outcomes were used less frequently. It is not known what functional outcome tools would be best suited to tracking the outcomes of DN for SRD.

\section{Supplementary information}

Supplementary information accompanies this paper at https://doi.org/10. 1186/s12998-020-00310-z.

Additional file 1: Table 4.1. Complete Data Cervical Region. Table 4.2. Complete Data TLP Region.

Additional file 2. Preferred Reporting Items for Systematic reviews and Meta-Analyses extension for Scoping Reviews (PRISMA-SCR) Checklist.

\section{Abbreviations}

AROM: Active range of motion; BAl: Beck anxiety index; BDI: Beck depression index; BPI: Brief pain inventory; BTA: Botulinum toxin-A; CADTH : Canadian Agency for Drugs and Technologies in Health; C-LF: Cervical lateral flexion; CLBP: Chronic low back pain; CNP: Chronic neck pain; CR: Case report; CRDYork: Centre for Reviews and Dissemination-University of York;

DASH: Disabilities of arm, shoulder, hand; DDN: Deep dry needling; DHI: Dizziness handicap inventory; DN: Dry needling; DN+: Dry needling with additional intervention; EIS: Electrical intramuscular stimulation;

EMG: Electromyography; FABQ: Fear avoidance beliefs questionnaire;

FMS: Fibromyalgia syndrome; f/u: Follow-up; G: Group; GDS-SF: Geriatric depression scale-short form; GRoC: Global rating of change; HPPT : Highpowered pain threshold; IASTM: Instrument assisted soft tissue mobilization; LBP: Low back pain; MET: Muscle energy technique; MPQ: McGill pain questionnaire; MPS: Myofascial pain syndrome; N/A: Not applicable; NEADLS: Nottingham extended activities of daily living scale; NDI: Neck disability index; NHP: Nottingham health profile; NP: Neck pain; NPDS: Neck pain disability scale; NPQ: Nonverbal personality questionnaire;

NPRS: Numeric pain rating scale; NTIS: National Technical Information Service; NYAM: New York Academy of Medicine; ODI: Oswestry disability index; OMT: Orthopedic manual therapy; PENS: Percutaneous electrical nerve stimulation; POMS: Profile of mood states; PPT: Pressure pain threshold; PROM: Patient reported outcome measures; PT: Physical therapy, physiotherapy; QL: Quadratus lumborum; QoL: Quality of life; RCT: Randomized controlled trial; RMQ: Rolland Morris disability questionnaire; ROM: Range of motion; SCM: Sternocleidomastoid muscle; SCS: Strain-counterstrain; SF-36: Short form-36; SI: Sacroiliac; SLR: Straight leg raise test; SNAG: Sustained natural apophyseal glide; SSR: Sympathetic skin response; STT: Soft tissue therapy; TENS: Transcutaneous electrical nerve stimulation; TFL: Tensor fasciae latae; TrP: Myofascial trigger point;

TSK: Tampa scale of kinesiophobia; US: Ultrasound; VAS: Visual analogue scale; WAD: Whiplash associated disorders; y.o.: Year old

\section{Acknowledgements}

Not applicable.

\section{Authors' contributions}

MFF and AJF both conceived of the project, as well as researched, analysed and contributed to writing the manuscript. Both authors read and approved the final manuscript.

\section{Authors' information}

MFF is associate professor of clinical sciences, University of Bridgeport College of Health Sciences, School of Chiropractic. AJF is a faculty member, University of Bridgeport College of Health Sciences, School of Chiropractic.

\section{Funding}

No funding was requested or received for this project.

Availability of data and materials

All data generated or analysed during this study are included in this published article [and its supplementary information files].

Ethics approval and consent to participate Not applicable.

Consent for publication

Not applicable.

Competing interests

The authors declare that they have no competing interests. 


\section{Received: 22 September 2019 Accepted: 15 April 2020}

\section{Published online: 11 May 2020}

\section{References}

1. Dunning J, Butts R, Mourad F, Young I, Flannagan S, Perreault T. Dry needling: a literature review with implications for clinical practice guidelines. Phys Ther Rev. 2014;19(4):252-65.

2. Zhou W, Benharash P. Effects and mechanisms of acupuncture based on the principle of meridians. J Acupunct Meridian Stud. 2014;7(4):190-3.

3. $\mathrm{Ga} \mathrm{H}$, Choi JH, Park $\mathrm{CH}$, Yoon HJ. Acupuncture needling versus lidocaine injection of trigger points in myofascial pain syndrome in elderly patients-a randomised trial. Acupunct Med. 2007;25(4):130-6.

4. Dommerholt J. Dry needling - peripheral and central considerations. J Man Manip Ther. 2011;19(4):223-7.

5. Dry needling applications: Matching technique with intent. 2016. https:// www.orthopt.org/uploads/content_files/2016_CSM_Handouts/Dry_ Needling_PMSIG.pdf. Accessed 3 Aug 2019.

6. Niddam DM, Chan RC, Lee SH, Yeh TC, Hsieh JC. Central modulation of pain evoked from myofascial trigger point. Clin J Pain. 2007;23(5):440-8.

7. Description of dry needling in clinical practice: An educational resource paper. 2013. http://www.apta.org/Statelssues/DryNeedling/ ClinicalPracticeResourcePaper. Accessed 3 Aug 2019.

8. Legge DI. A history of dry needling. J. Musculoskelet Pain. 2014;22(3):301-7.

9. Donnelly JM, Fries LM, Cicchetti CS, Fernandez de las Penas C. Trigger point injection and dry needling. In: Donnelly JM, Fernandez de las Penas C, Finnegan $M$, Freeman $J L$, editors. Myofascial pain and dysfunction. The Trigger point manual 3rd ed. Philadelphia: Wolters Kluwer; 2019. p. 769.

10. Ong J, Claydon LS. The effect of dry needling for myofascial trigger points in the neck and shoulders: A systematic review and meta-analysis. J Bodyw Mov Ther. 2014:18(3):390-8.

11. Hu HT, Gao H, Ma RJ, Zhao XF, Tian HF, Li L. Is dry needling effective for low back pain?: A systematic review and PRISMA-compliant meta-analysis. Medicine (Baltimore). 2018;97(26):e11225.

12. Gattie E, Cleland JA, Snodgrass S. The Effectiveness of Trigger Point Dry Needling for Musculoskeletal Conditions by Physical Therapists: A Systematic Review and Meta-analysis. J Orthop Sports Phys Ther. 2017;47(3): $133-49$

13. Liu L, Huang QM, Liu QG, Ye G, Bo CZ, Chen MJ, et al. Effectiveness of dry needling for myofascial trigger points associated with neck and shoulder pain: a systematic review and meta-analysis. Arch Phys Med Rehabil. 2015; 96(5):944-55.

14. Liu L, Huang QM, Liu QG, Thitham N, Li LH, Ma YT, et al. Evidence for dry needling in the management of myofascial trigger points associated with low back pain: A systematic review and meta-analysis. Arch Phys Med Rehabil. 2018;99(1):144-52.

15. Espejo-Antúnez L, Tejeda JF, Albornoz-Cabello M, Rodríguez-Mansilla J, de la Cruz-Torres B, Ribeiro F, et al. Dry needling in the management of myofascial trigger points: A systematic review of randomized controlled trials. Complement Ther Med. 2017;33:46-57.

16. Murphy DR. Clinical reasoning in spine pain, vol, I: Primary management of low back disorders using the CRISP protocols. A practical evidence-based guide. Pawtucket: CRISP Education and Research LLC; 2013.

17. Murphy DR. Clinical reasoning in spine pain, vol, II: Primary management of cervical disorders using the CRISP protocols. Case studies in primary spine care. Cranston: CRISP Education and Research LLC; 2016.

18. Desai MJ, Saini V, Saini S. Myofascial pain syndrome: a treatment review. Pain Ther. 2013;2(1):21-36.

19. Arksey H, O'Malley L. Scoping studies: towards a methodological framework. Int J Soc Res Methodol. 2005;8(1):19-32.

20. Levac D, Colquhoun H, O'Brien KK. Scoping studies: advancing the methodology. Implement Sci. 2010;5:69. https:/doi.org/10.1186/1748-5908-5-69.

21. Peters MDJ, Godfrey CM, Khalil H, Mclnerney P, Parker D, Soares CB. Guidance for conducting systematic scoping reviews. Int J Evid Based Healthc. 2015;13(3):141-6.

22. Moher D, Liberati A, Tetzlaff J, Altman DG, Group P. Preferred reporting items for systematic reviews and meta-analyses: the PRISMA statement. PLoS Med. 2009;6(7):e1000097.

23. Couto C, de Souza ICC, Torres ILS, Fregni F, Caumo W. Paraspinal stimulation combined with trigger point needling and needle rotation for the treatment of myofascial pain: a randomized sham-controlled clinical trial. Clin J Pain. 2014;30(3):214-23.
24. Raessadat SA, Rayegani SM, Sadeghi F, Rahimi-Dehgolan S. Comparison of ozone and lidocaine injection efficacy vs dry needling in myofascial pain syndrome patients. J Pain Res. 2018;11:1273-9.

25. Segura-Perez M, Hernandez-Criado MT, Calvo-Lobo C, Vega-Piris L, Fernandez-Martin R, Rodriguez-Sanz D. A multimodal approach for myofascial pain: a prospective study. J Manipulative Physiol Ther. 2017;40(6): 397-403.

26. Srbely JZ, Dickey JP, Lee D, Lowerison M. Dry needle stimulation of myofascial trigger points evokes segmental anti-nociceptive effects. J Rehabil Med. 2010;42(5):463-8.

27. Yaghoubi Z, Pardehshenas H, Takamjani IE. The effect of upper trapezius muscle dry needling treatment on sleep quality: A case report. J Bodyw Mov Ther. 2018:22(2):333-6.

28. Ronel D, Gabbay O, Esterson A, Brand R, Vulfsons S. Twenty thousand needles under the sea. Trigger point dry needling aboard an Israeli Navy Submarine: A case report. Mil Med. 2018;183(11-12):e762-4.

29. Lapeer GL. Postsurgical myofascial pain resolved with dry-needling. Treatment protocol and case report. Cranio. 1989;7(3):243-4.

30. Lewit K. The needle effect in the relief of myofascial pain. Pain. 1979;6(1):8390.

31. Gunn CC, Milbrandt WE, Little AS, Mason KE. Dry needling of muscle motor points for chronic low-back pain: a randomized clinical trial with long-term follow-up. Spine. 1980;5(3):279-91.

32. Ingber RS. Iliopsoas myofascial dysfunction: a treatable cause of "failed" low back syndrome. Arch Phys Med Rehabil. 1989;70(5):382-6.

33. Abbaszadeh-Amirdehi M, Ansari NN, Naghdi S, Olyaei G, Nourbakhsh MR. Therapeutic effects of dry needling in patients with upper trapezius myofascial trigger points. Acupunct Med. 2017;35(2):85-92.

34. Aridici R, Yetisgin A, Boyaci A, Tutoglu A, Bozdogan E, Sen Dokumaci D, et al. Comparison of the efficacy of dry needling and high-power pain threshold ultrasound therapy with clinical status and sonoelastography in myofascial pain syndrome. Am J Phys Med Rehabil. 2016;95(10):e149-58.

35. Ay S, Evcik D, Tur BS. Comparison of injection methods in myofascial pain syndrome: a randomized controlled trial. Clin Rheumatol. 2010;29(1):19-23.

36. Aydin T, Dernek B, Senturk Ege T, Karan A, Aksoy C. The Effectiveness of dry needling and exercise therapy in patients with dizziness caused by cervical myofascial pain syndrome; prospective randomized clinical study. Pain Med. 2019;20(1):153-60.

37. Bond BM, Kinslow C. Improvement in clinical outcomes after dry needling in a patient with occipital neuralgia. J Can Chiropr Assoc. 2015:59(2):101-10.

38. Campa-Moran I, Rey-Gudin E, Fernandez-Carnero J, Paris-Alemany A, GilMartinez A, Lerma Lara S, et al. Comparison of dry needling versus orthopedic manual therapy in patients with myofascial chronic neck pain: a single-blind, randomized pilot study. Pain Res Treat. 2015;2015:327307.

39. Cerezo-Tellez E, Lacomba MT, Fuentes-Gallardo I, Mayoral Del Moral O, Rodrigo-Medina B, Gutierrez OC. Dry needling of the trapezius muscle in office workers with neck pain: a randomized clinical trial. J Man Manip Ther. 2016;24(4):223-32

40. Cerezo-Tellez E, Torres-Lacomba M, Fuentes-Gallardo I, Perez-Munoz M,

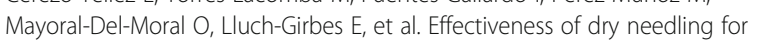
chronic nonspecific neck pain: a randomized, single-blinded, clinical trial. Pain. 2016;157(9):1905-17.

41. Chu J. Does EMG (dry needling) reduce myofascial pain symptoms due to cervical nerve root irritation? Electromyogr Clin Neurophysiol. 1997;37(5): 259-72.

42. De Meulemeester KE, Castelein B, Coppieters I, Barbe T, Cools A, Cagnie B. Comparing trigger point dry needling and manual pressure technique for the management of myofascial neck/shoulder pain: a randomized clinical trial. J Manipulative Physiol Ther. 2017:40(1):11-20.

43. Eroglu PK, Yilmaz O, Bodur H, Ates C. A comparison of the efficacy of dry needling, lidocaine injection, and oral flurbiprofen treatments in patients with myofascial pain syndrome: a double-blind (for injection, groups only), randomized clinical trial. Arch Rheumatol. 2013;28(1):38-46.

44. Fernandez-Carnero J, Gilarranz-de-Frutos L, Leon-Hernandez JV, PecosMartin D, Alguacil-Diego I, Gallego-lzquierdo T, et al. Effectiveness of different deep dry needling dosages in the treatment of patients with cervical myofascial pain: a pilot RCT. Am J Phys Med Rehabil. 2017;96(10): 726-33.

45. Ga H, Choi JH, Park CH, Yoon HJ. Dry needling of trigger points with and without paraspinal needling in myofascial pain syndromes in elderly patients. J Altern Complement Med. 2007;13(6):617-24. 
46. Gerber LH, Shah J, Rosenberger W, Armstrong K, Turo D, Otto P, et al. Dry needling alters trigger points in the upper trapezius muscle and reduces pain in subjects with chronic myofascial pain. PM R. 2015;7(7):711-8.

47. Gerber LH, Sikdar S, Aredo JV, Armstrong K, Rosenberger WF, Shao H, et al, Beneficial effects of dry needling for treatment of chronic myofascial pain persist for 6 weeks after treatment completion. PM R. 2017;9(2):105-12.

48. Guthrie RM, Chorba R. Physical therapy treatment of chronic neck pain a discussion and case study: using dry needling and battlefield acupuncture. J Spec Oper Med. 2016;16(1):1-5

49. Hayta E, Umdu NM. A randomized trial to study the comparison of trigger point dry needling verses kinesio taping technique in myofascial pain syndrome during a 3-month follow-up. Int J Physiother. 2016;3(5):490-6.

50. Hong CZ. Lidocaine injection versus dry needling to myofascial trigger point. The importance of the local twitch response. Am J Phys Med Rehabil. 1994;73(4):256-63.

51. Ilbuldu E, Cakmak A, Disci R, Aydin R. Comparison of laser, dry needling, and placebo laser treatments in myofascial pain syndrome. Photomed Laser Surg. 2004;22(4):306-11.

52. Irnich D, Behrens N, Gleditsch JM, Stor W, Schreiber MA, Schops P, et al. Immediate effects of dry needling and acupuncture at distant points in chronic neck pain: results of a randomized, double-blind, sham-controlled crossover trial. Pain. 2002;99(1-2):83-9.

53. Jimbo S, Atsuta $Y$, Kobayashi T, Matsuno T. Effects of dry needling at tender points for neck pain (Japanese: katakori): near-infrared spectroscopy for monitoring muscular oxygenation of the trapezius. J Orthop Sci. 2008;13(2): 101-6.

54. Kamanli A, Kaya A, Ardicoglu O, Ozgocmen S, Zengin FO, Bayik Y. Comparison of lidocaine injection, botulinum toxin injection, and dry needling to trigger points in myofascial pain syndrome. Rheumatol Int. 2005;25(8):604-11.

55. Karakurum B, Karaalin O, Coskun O, Dora B, Ucler S, Inan L. The 'dry-needle technique': intramuscular stimulation in tension-type headache. Cephalalgia. 2001;21(8):813-7.

56. Lari YA, Okhovatian F, Naimi SS, Baghban AA. The effect of the combination of dry needling and MET on latent trigger point upper trapezius in females. Man Ther. 2016;21:204-9.

57. Leon-Hernandez JV, Martin-Pintado-Zugasti A, Frutos LG, Alguacil-Diego IM, de la Llave-Rincon Al, Fernandez-Carnero J. Immediate and short-term effects of the combination of dry needling and percutaneous TENS on postneedling soreness in patients with chronic myofascial neck pain. Braz J Phys Ther. 2016;20(5):422-31.

58. Llamas-Ramos R, Pecos-Martin D, Gallego-Izquierdo T, Llamas-Ramos I, PlazaManzano G, Ortega-Santiago R, et al. Comparison of the short-term outcomes between trigger point dry needling and trigger point manual therapy for the management of chronic mechanical neck pain: a randomized clinical trial. J Orthop Sports Phys Ther. 2014;44(11):852-61.

59. Mejuto-Vazquez MJ, Salom-Moreno J, Ortega-Santiago R, Truyols-Dominguez S, Fernandez-de-Las-Penas C. Short-term changes in neck pain, widespread pressure pain sensitivity, and cervical range of motion after the application of trigger point dry needling in patients with acute mechanical neck pain: a randomized clinical trial. J Orthop Sports Phys Ther. 2014:44(4):252-60.

60. Myburgh C, Hartvigsen J, Aagaard P, Holsgaard-Larsen A. Skeletal muscle contractility, self-reported pain and tissue sensitivity in females with neck/ shoulder pain and upper Trapezius myofascial trigger points- a randomized intervention study. Chiropr Man Therap. 2012;20(1):36.

61. Ozden AV, Alptekin HK, Esmaeilzadeh S, Cihan C, Aki S, Aksoy C, et al. Evaluation of the Sympathetic Skin Response to the Dry Needling Treatment in Female Myofascial Pain Syndrome Patients. J Clin Med Res. 2016:8(7):513-8

62. Patra CP, Mohanty P, Gautam AP. Effectiveness of C1-C2 sustained natural apophyseal glide combined with dry needling on pressure point threshold and headache disability in cervicogenic headache. Asian J Pharm Clin Res. 2018;11(1):171-4.

63. Pavkovich R. The use of dry needling for a subject with acute onset of neck pain: a case report. Int J Sports Phys Ther. 2015;10(1):104-13.

64. Priyanka M, Tilak Francis TG. Compare the effectiveness of dry needling therapy versus cryotherapy on patients with upper trapezius trigger. Indian J Physiother Occup Ther. 2017;11(3):183-6.

65. Rayegani SM, Bayat M, Bahrami MH, Raeissadat SA, Kargozar E. Comparison of dry needling and physiotherapy in treatment of myofascial pain syndrome. Clin Rheumatol. 2014;33(6):859-64.
66. Sato K, Oliviera A, Lima A. Effectiveness of dry needling reduction myofascial trigger point pain in the trapezius muscle. J Pain. 2014;15(4):S117.

67. Sillevis $R$. The use of dry needling in combination with manual therapy techniques for a patient with cervicogenic headache: a case report. J Phys Ther. 2011;3:9-18.

68. Sedighi A, Nakhostin Ansari N, Naghdi S. Comparison of acute effects of superficial and deep dry needling into trigger points of suboccipital and upper trapezius muscles in patients with cervicogenic headache. J Bodyw Mov Ther. 2017;21(4):810-4.

69. Segura-Orti E, Prades-Vergara S, Manzaneda-Pina L, Valero-Martinez R, PoloTraverso JA. Trigger point dry needling versus strain-counterstrain technique for upper trapezius myofascial trigger points: a randomised controlled trial. Acupunct Med. 2016;34(3):171-7.

70. Shanmugam S, Mathias L. Immediate Effects of Paraspinal Dry Needling in Patients with Acute Facet Joint Lock Induced Wry Neck. J Clin Diagn Res. 2017;11(6):YM01-YM3

71. Sterling M, Vicenzino B, Souvlis T, Connelly LB. Dry-needling and exercise for chronic whiplash-associated disorders: a randomized single-blind placebocontrolled trial. Pain. 2015;156(4):635-43.

72. Tasoglu O, Sahin Onat S, Boluk H, Tasoglu I, Ozgirgin N. Comparision of two different dry-needling techniques in the treatment of myofascial pain syndrome. Agri. 2017;29(1):9-16.

73. Tekin L, Akarsu S, Durmus O, Cakar E, Dincer U, Kiralp MZ. The effect of dry needling in the treatment of myofascial pain syndrome: a randomized double-blinded placebo-controlled trial. Clin Rheumatol. 2013;32(3):309-15.

74. Wang G, Gao Q, Hou J, Li J. Effects of Temperature on Chronic Trapezius Myofascial Pain Syndrome during Dry Needling Therapy. Evid Based Complement Alternat Med. 2014;2014:638268.

75. Venancio RA, Alencar FGP, Zamperini C. Different substances and dryneedling injections in patients with myofascial pain and headaches. Cranio. 2008;27(2):96-103.

76. Venancio RA, Alencar FGP, Zamperini C. Botulinum toxin, lidocaine, and dryneedling injections in patients with myofascial pain and headaches. Cranio. 2009;27(1):46-53.

77. Zheng Y, Shi D, Wu X, Gu M, Ai Z, Tang K, et al. Ultrasound-guided miniscalpelneedle release versus dry needling for chronic neck pain: a randomized controlled trial. Evid Based Complement Alternat Med. 2014;2014:235817.

78. Ziaeifar M, Arab AM, Karimi N, Nourbakhsh MR. The effect of dry needling on pain, pressure pain threshold and disability in patients with a myofascial trigger point in the upper trapezius muscle. J Bodyw Mov Ther. 2014;18(2):298-305.

79. Ziaeifar M, Arab AM, Nourbakhsh MR. Clinical effectiveness of dry needling immediately after application on myofascial trigger point in upper trapezius muscle. J Chiropr Med. 2016;15(4):252-8.

80. Ahn K, Jhun HJ, Lim TK, Lee YS. Fluoroscopically guided transforaminal epidural dry needling for lumbar spinal stenosis using a specially designed needle. BMC Musculoskelet Disord. 2010;11:180.

81. Anandkumar S, Manivasagam M. Effect of fascia dry needling on nonspecific thoracic pain - a proposed dry needling grading system. Physiother Theory Pract. 2017;33(5):420-8.

82. Castro-Sanchez AM, Garcia-Lopez H, Mataran-Penarrocha GA, FernandezSanchez M, Fernandez-Sola C, Granero-Molina J, Aguilar-Ferrandiz ME. Effects of dry needling on spinal mobility and trigger points in patients with fibromyalgia syndrome. Pain Physician. 2017;20(2):37-52.

83. Huguenin L, Brukner P, McCrory P, Smith P, Wajswelner H, Bennell K. Effect of dry needling of gluteal muscles on straight leg raise: a randomised, placebo controlled, double blind trial. Br J Sports Med. 2005;39(2):84-90.

84. Koppenhaver SL, Walker MJ, Rettig C, Davis J, Nelson C, Su J, Fernandez-delas-Penas C, Hebert JJ. The association between dry needling-induced twitch response and change in pain and muscle function in patients with low back pain: a quasi-experimental study. Physiotherapy. 2017;103(2):131-7.

85. Koppenhaver SL, Walker MJ, Smith RW, Booker JM, Walkup ID, Su J, Hebert $J$ J, Flynn T. Baseline examination factors associated with clinical improvement after dry needling in individuals with low back pain. J Orthop Sports Phys Ther. 2015;45(8):604-12.

86. Koppenhaver SL, Walker MJ, Su J, McGowen JM, Umlauf L, Harris KD, Ross MD. Changes in lumbar multifidus muscle function and nociceptive sensitivity in low back pain patient responders versus non-responders after dry needling treatment. Man Ther. 2015;20(6):769-76.

87. Mahmoudzadeh A, Rezaeian ZS, Karimi A, Dommerholt J. The effect of dry needling on the radiating pain in subjects with discogenic low-back pain: a randomized control trial. J Res Med Sci. 2016;21(1):86-95. 
88. Pecos-Martin D, Montañez-Aguilera FJ, Gallego-Izquierdo T, Urraca-Gesto A, Gómez-Conesa A, Romero-Franco N, Plaza-Manzano G. Effectiveness of dry needling on the lower trapezius in patients with mechanical neck pain: a randomized controlled trial. Arch Phys Med Rehab. 2015;96(5):775-81.

89. Perez-Palomares S, Olivan-Blazquez B, Magallon-Botaya R, De-la-TorreBeldarrain ML, Gaspar-Calvo E, Romo-Calvo L, Garcia-Lazaro R, SerranoAparicio B. Percutaneous electrical nerve stimulation versus dry needling: effectiveness in the treatment of chronic low back pain. J Musculoskelet Pain. 2010;18(1):23-30.

90. Rainey CE. The use of trigger point dry needling and intramuscular electrical stimulation for a subject with chronic low back pain: a case report. Int J Sports Phys Ther. 2013;8(2):145-61.

91. Tellez-Garcia M, de-la-Llave-Rincon Al, Salom-Moreno J, Palacios-Cena M, Ortega-Santiago R, Fernandez-de-las-Penas C. Neuroscience education in addition to trigger point dry needling for the management of patients with mechanical chronic low back pain: a preliminary clinical trial. J Bodyw Mov Ther. 2015;19(3):464-72.

92. Tuzun EH, Gildir S, Angin E, Tecer BH, Dana KO, Malkoc M. Effectiveness of dry needling versus a classical physiotherapy program in patients with chronic low-back pain: a single, randomized controlled trial. J Phys Ther Sci. 2017;29(9):1502-9.

93. Rock JM, Rainey CE. Treatment of nonspecific thoracic spine pain with trigger point dry needling and intramuscular stimulation: a case series. Int J Sports Phys Ther. 2014;9(5):699-711.

94. Tricas-Moreno JM, Lucha-Lopez MO, Lucha-Lopez AC, Salavera-Bordas C, Vidal-Peracho C. Optimizing physical therapy for ankylosing spondylitis: a case study in a young football player. J Phys Ther Sci. 2016;28(4):1392-7.

95. Wang G, Gao Q, Li J, Tian Y, Hou J. Impact of needle diameter on long-term dry needling treatment of chronic lumbar myofascial pain syndrome. Am J Phys Med Rehabil. 2016;95(7):483-94.

96. Rubin DI. Epidemiology and risk factors for spine pain. Neurol Clin. 2007; 25(2):353-71.

97. Hoy D, March L, Brooks P, Blyth F, Woolf A, Bain C, et al. The global burden of low back pain: estimates from the global burden of disease 2010 study. Ann Rheum Dis. 2014;73(6):968-74.

98. Fejer R, Kyvik KO, Hartvigsen J. The prevalence of neck pain in the world population: a systematic critical review of the literature. Eur Spine J. 2006; 15(6):834-48.

99. Dommerholt J, Fernandez-de-las-Penas C, Petersen SM. Needling: is there a point? J Man Manip Ther. 2019;27(3):125-7.

\section{Publisher's Note}

Springer Nature remains neutral with regard to jurisdictional claims in published maps and institutional affiliations.

Ready to submit your research? Choose BMC and benefit from:

- fast, convenient online submission

- thorough peer review by experienced researchers in your field

- rapid publication on acceptance

- support for research data, including large and complex data types

- gold Open Access which fosters wider collaboration and increased citations

- maximum visibility for your research: over $100 \mathrm{M}$ website views per year

At $\mathrm{BMC}$, research is always in progress.

Learn more biomedcentral.com/submissions 